\title{
Movimentos sociais e Judiciário: invertendo a condição de protagonista do discurso
}

\author{
Social movements and Judiciary: changing the protagonist of the speech
}

\author{
Gretha Leite Maia* \\ Maria Tatiana Sousa**
}

\section{Resumo}

O artigo objetiva articular um estudo sobre o Poder Judiciário brasileiro e uma pesquisa sobre os movimentos sociais, na qual se inclui uma pesquisa de campo junto a três movimentos organizados no Ceará. Inicia por um estudo analítico da constituição do Judiciário enquanto Poder do Estado no Brasil, alcançando os estudos contemporâneos sobre o Judiciário brasileiro. Os estudos contemporâneos sustentam a proposta de aproximação entre o Judiciário e os movimentos sociais. Em seguida, objetivando verificar a correspondente efetivação dessa aproximação, realiza um estudo sobre movimentos sociais e uma consulta junto a três movimentos sociais de significativa atuação no Ceará nas últimas décadas para colher, a partir dos que dizem os movimentos, os relatos dessa aproximação. Trata-se de uma metodologia que busca inverter a condição de protagonista do discurso, verificando junto aos movimentos os relatos de experiências de resolução de conflitos e demandas pela via jurisdicional. O trabalho é composto de um estudo histórico e teórico do Poder Judiciário no Brasil e um estudo teórico e empírico sobre os movimentos sociais. Trata-se de pesquisa bibliográfica, transdisciplinar, com base teórica que alia estudos do Direito, da História e da Sociologia, e uma pesquisa empírica qualitativa que se realizou por meio da coleta de dados junto aos movimentos CEARAH Periferia, MST Ceará, e coletivo "Quem dera ser um peixe". Conclui que o Judiciário e os movimentos sociais ainda mantém uma distância institucional, estabelecida por décadas de afastamento e desconhecimento mútuo.

Palavras-chave: Movimentos sociais. Judiciário. Acesso.

\section{Abstract}

The article aims to articulate a research of Judiciary and a research of social movements, in which is included a survey of three movements organized in Ceará. The first part is an analytical study of the Judiciary installation in Brazil, reaching the contemporary studies on the Brazilian judiciary. These contemporary studies claim a connection between Judiciary and social movements. The second part is a study about social movements, including a survey of three social movements: CEARAH Periferia, MST Ceará and "Quem dera ser um peixe". The research aims to investigate how was the approach between Judiciary and social movements, especially from the narratives collected from social movements. It is a multidisciplinary, bibliographic and qualitative empirical research. Concludes that judiciary and social movements in Brazil still maintain an institutional distance, established by many times of separation and unknowingness of each other.

Keywords: Social movements. Judiciary. Access.

\section{Introdução}

Os estudos sobre o Poder Judiciário se multiplicaram nas últimas décadas. Considerando em especial a literatura que tem por referência os países europeus, afirma-se que, após a era do "big goverment", no

Doutora em Direito pela Universidade Federal do Ceará (UFC). Mestre e graduada em Direito pela Universidade Federal do Ceará. Professora adjunta do Departamento de Direito Processual da Universidade Federal do Ceará. Fortaleza - CE - Brasil. E-mail: grethaleitemaia@gmail.com. Graduada em Letras pela Universidade Federal do Ceará. Graduanda em Direito pela Universidade Federal do Ceará. Pesquisadora PIBIC 20142015/UFC. Bolsista FUNCAP. Fortaleza - CE - Brasil. E-mail: taty_1309@hotmail.com. 
século XIX, e a era do Parlamento, no século XX, o século XXI se inicia como o momento de protagonismo do Poder Judiciário. Tal expectativa tem orientado o mundo no qual se firmou o Estado de direito (apoiado na estruturação burocrática de três Poderes) no sentido de conhecer melhor o Judiciário. No Brasil, esse movimento em direção ao conhecimento do Judiciário também se deu em várias vertentes. Tem-se desde um discurso que o identifica como o garantidor da efetivação dos direitos fundamentais até um cenário no qual se identifica a tendência de torná-lo um assegurador da moralização da política. Como pauta de pesquisa, esse interesse se dissemina em estudos multidisciplinares, que envolvem vários saberes, desde a ciência política até as ciências estatísticas e de gestão administrativa dos órgãos e tribunais jurisdicionais.

Nas academias jurídicas também se instalou uma tendência de ampliação dos estudos do Judiciário. Nesses estudos, revela-se de modo mais agudo a precariedade da pesquisa jurídica no Brasil, uma área ainda em construção. Os pesquisadores se concentram nos programas de pós-graduação, uma vez que os cursos de graduação ainda mantêm um padrão tecnicista e generalista. E, mesmo junto aos programas de pós-graduação, ainda é perceptível a manutenção de um padrão de isolamento: em geral, as pesquisas jurídicas se referenciam nos estudos e escritos jurídicos. Em outras palavras: no que o Judiciário diz de si mesmo, ou no que se pensa sobre o Direito a partir de suas próprias formas e institutos (a partir de quem o propõe e estabelece, não de quem o consome).

Esse trabalho é uma tentativa de inversão desse olhar. Para isso, o ponto de partida formam os estudos mais relevantes sobre o Poder Judiciário brasileiro, incluindo pesquisas historiográficas, realizadas inclusive por autores estrangeiros, e pesquisas recentes capitaneadas por núcleos de estudos e pesquisas sociais e políticas. Em seguida, foi posta como pauta da pesquisa o modo como os movimentos sociais percebem e compreendem a atuação do Judiciário. Com isso, pretende-se fazer uma permuta no objeto prevalente nas pesquisas jurídicas, qual seja: o Direito e suas formas e estruturas.

O estudo dos movimentos sociais, entretanto, não se permite confinar em termos teóricos, pois demanda uma dinâmica própria de investigações, cujo objeto é instável, para além das formas e estruturas que assumam. Assim, realizou-se tanto uma investigação teórica por meio de pesquisa bibliográfica sobre os movimentos sociais e sobre os novos movimentos sociais no Brasil quanto uma investigação empírica por meio de coleta de dados junto a três movimentos sociais significativos, com atuação nos últimos 10 anos no estado do Ceará. A pesquisa de campo tem por objetivo trazer à luz novas compreensões, novos olhares sobre o Poder Judiciário brasileiro.

Essa aproximação entre o judiciário e os movimentos sociais, considerados enquanto objeto de pesquisa, ocorre em razão do que se afirmou sobre o Judiciário no papel de realizador da justiça social, sustentado no discurso de garantidor dos Direitos Humanos. Nesse contexto, surge, em especial no discurso jurídico, a figura de um "super" Judiciário, tido como capaz de modificar quadros sociais simultaneamente estabelecidos e contestados desde o processo de colonização. Uma magistratura posta para efetivar direitos, como o acesso à saúde, à moradia e à educação. Assim, a esse Judiciário é concedido o poder de intervir nas políticas públicas, no orçamento dos entes federativos, dentre outros aspectos que não estariam, de práxis, ligados a sua competência. O Judiciário como partícipe central e legítimo de ações políticas.

Ocorre que, no campo da política, tradicionalmente atuaram, de forma central, partidos políticos, sindicatos e movimentos sociais organizados. Os movimentos sociais no Brasil redemocratizado foram, também, assumindo novas feições e protagonismos. Articulados em torno de novas demandas, os movimentos sociais deixaram de ser somente visualizados nas lutas por direitos trabalhistas, desdobramentos da tensão capital-trabalho, e se expandiram em múltiplas demandas por direitos, atravessados por noções que vão da identidade cultural aos direitos de diversidade sexual. Esses ditos novos movimentos sociais desafiam igualmente as categorias pensadas no século XX para dar conta de um pensamento sistematizado sobre eles. Assim como os discursos do novo Judiciário, estabelece-se o discurso sobre os novos movimentos sociais. 
Dessa forma, essa pesquisa busca questionar como essa transformação anunciada, pensada e esperada, seja do Poder Judiciário, seja dos novos movimentos sociais no Brasil pós-88, ocorreu e o que realmente se alcançou com relação às demandas levadas ao Judiciário pelos movimentos sociais. $O$ objetivo dessa pesquisa é contrastar os estudos estabelecidos e os dados coletados junto aos próprios movimentos sociais, escolhendo, numa amostragem por conveniência, três movimentos organizados de defesa de direitos no estado do Ceará.

\section{Breve história do Judiciário brasileiro}

A função desempenhada pelo Poder Judiciário dentro do projeto do Estado de direito não é estabelecida de forma estática, definitiva, mas a partir de definições que o Estado se impõe, enquanto fim, e a partir do jogo de interesses que se estabelece na realidade social. Portanto, é historicamente que se constitui o que se pode chamar de papel do Judiciário. Assim, para que se compreenda melhor o papel do Judiciário brasileiro, é imprescindível um regresso à instalação dos juízes e tribunais no Brasil. Sua gênese, no período colonial, é datada pela chegada, em 1609, dos primeiros magistrados, que atuavam na Corte portuguesa orientados por funções institucionais determinadas.

De acordo com Schwartz (2011), no período colonial, Portugal dispunha de um grupo de letrados que tinham uma estreita ligação com a Coroa: além de respeitarem a lei e a ordem, objetivavam encontrar soluções legais para os problemas práticos do governo português no território colonial. Diante da necessidade de bem administrar o Império Ultramarino, a Coroa busca essa classe de magistrados como uma aliada para controlar os conflitos existentes na colônia. Os magistrados ofereciam ao rei um meio burocrático de controle e, uma vez que dependiam do poder real para atingir objetivos em suas carreiras, poderia ser considerados leais aos objetivos estabelecidos pela Coroa. Uma magistratura para assegurar o modelo de exploração baseado no mercantilismo e no colonialismo, conforme o contexto de formação do Brasil no Atlântico Sul descrito por Alencastro (2000).

Nessa perspectiva, os magistrados, vistos como uma criação real, são a espinha dorsal do governo. A chegada da Relação (Tribunal Superior do Brasil), formada inicialmente por dez desembargadores, não foi compreendida como um poder autônomo e imparcial, mas como um meio pelo qual os agentes da elite portuguesa ligados à Coroa pudessem garantir seus interesses. Verificada a importância da aliança Coroa-magistrados, ocorreu inclusive a outros grupos sociais também conseguir benefícios por meio desses homens letrados. Como evidencia Schwartz (2011, p.119): "O padre Cardim e seus colegas jesuítas também viam a Relação como provável aliada. Os senhores de engenho esperavam usá-la contra os comerciantes, e os jesuítas como esforço contra os senhores de engenho".

Assim, foi estabelecida uma tensão entre os magistrados. De um lado, senhores de engenho e jesuítas, e, de outro, projeção do jogo de interesses entre eles e os interesses da metrópole. $O$ fato mais significativo dessa tensão talvez seja a instituição de uma lei, que acompanhou a instalação da Relação no Brasil, que previa o fim dos excessos e dos abusos na escravização dos indígenas, declarando que os índios, cristãos ou pagãos, eram, por natureza, homens livres e, por isso, tinham direito a salários por seus trabalhos.

Em um primeiro momento, sem considerar a economia colonial, a lei pode ser vista como apenas mais uma norma no ordenamento jurídico, embalada em discurso humanitário. No entanto, ela estabelecida um ônus aos senhores de engenho que precisavam dessa mão de obra para garantir seus negócios, e, ao mesmo tempo, ampliava o poder dos negreiros portugueses. Ademais, a lei também previa que "todos os índios que tinham sido capturados ilegalmente seriam libertados e todas as notas fiscais de compras ou decisões judiciais que justificassem sua escravização eram agora consideradas contrárias à lei e, portanto, nulas e sem validade" (SCHWARTZ, 2011, p.120). Como a aplicação da lei era função da Relação, criouse uma atmosfera de impopularidade para o órgão recém-instalado. Segundo Schwartz (2011, p.121), "parece que essa não era bem uma tática destinada a angariar popularidade para a Relação". 
Vale ressaltar que a Coroa destinou a Relação não apenas a função de julgar. A Relação acumulava cargos administrativos e também funções investigatórias. Tal acontecia, segundo Schwartz (2011, p.137), porque:

\begin{abstract}
A Coroa via a Relação como leal e inteligente fonte de informação, cujas opiniões em questões locais sempre levavam em conta os interesses reais. O chanceler podia corresponder-se diretamente com o trono e assim ter papel ativo na formulação política. Os magistrados, vistos pela Coroa como funcionários leais e confiáveis, geralmente eram convocados para realizar tarefas não judiciais. No Brasil, a Relação funcionou com frequência como conselho consultivo em questões de bem-estar comum. Ao voltar para Portugal, tanto os desembargadores como os governadores-gerais eram chamados para aconselhar a Coroa no que dizia respeito a problemas ou nomeações no Brasil.
\end{abstract}

Além disso, a influência do Judiciário nos aspectos políticos também decorre do grande contingente de população rural em relação à urbana. Dessa condição surge, segundo Carvalho (2003), o fenômeno da ocupação múltipla, sendo comum uma pessoa (especialmente os letrados) ter mais de uma ocupação. Tal situação atingia principalmente os magistrados que apresentavam condições para atuarem não apenas na defesa e aplicação da lei, mas também nas tarefas do Estado: "[...] os magistrados apresentavam a mais perfeita combinação de elementos intelectuais, ideológicos e práticos favoráveis ao estatismo. $\mathrm{Na}$ verdade, foram os mais completos construtores de Estado no Império, especialmente os da geração coimbrã" (SCHWARTZ, 2011, p. 99).

Dessa forma, faz-se clara a influência que os magistrados tinham nesse período histórico e como eram figuras fortes no cenário político, principalmente porque exerciam cargos como conselheiros do Conselho de Estado. Além disso, é importante ressaltar a presença mais forte desses magistrados em legislaturas dominadas pelo Partido Conservador, dado que pode ser esclarecido com o levantamento feito por Carvalho (2003, p.109): um percentual de $50 \%$ dos magistrados era ligado, direta ou indiretamente, à propriedade rural, e uma porcentagem muito menor apontava uma ligação com a atividade comercial. Essa informação ratifica que a "elite era controlada pelos donos de terra, e, portanto, também o era o Estado", já que os magistrados eram, em boa parte, proprietários de terra e membros do poder.

Nesse contexto, conforme Carvalho (2003), a elite que ocupava os cargos públicos, devido à dependência financeira que tinham em relação aos empregos públicos, tinha interesse material muito forte na manutenção e na expansão da burocracia que se estabelecia no Brasil. Dessa forma, instalou o patrimonialismo, que caracteriza a relação sociedade-Estado no Brasil. Mesmo sendo uma boa parte dos magistrados também proprietários de terras, por vezes a magistratura ia de encontro aos interesses de latifundiários para votarem projetos a favor do governo, garantindo sua manutenção e de seus familiares no serviço público.

Esse cenário se mantém durante o I Império brasileiro e perdura até a proclamação da República. Antes disso, a reforma do Judiciário, levada a feito em 1871, pontuou o esforço de profissionalização dos juízes, determinando o afastamento das tarefas não vinculadas ao cargo. De acordo com Carvalho (2003, p.181), "a abundância de bacharéis também pressionava nesta direção, de vez que a acumulação de cargos políticos e judiciários reduzia a oportunidade de emprego para os novos”. Durante a Primeira República, estabelecido o federalismo, o Judiciário é marcado pela ausência de garantias, como a inamovibilidade, vitaliciedade e irredutibilidade de vencimentos dos juízes estaduais, o que garantiu a manipulação desse Poder em favor dos chefes políticos locais, os chamados coronéis.

\title{
3 A expectativa de um novo Judiciário no Brasil
}

O Estado brasileiro passará por uma estruturação ampla durante os anos 30 e 40 do século XX. O agigantamento da estrutura administrativa (exemplificados pela criação dos Ministérios da Educação e da Saúde) fará do Poder Executivo o centro de acumulação de poderes e funções, sendo talvez o período no qual o Executivo mais interferiu no Judiciário para reduzir suas competências. O Brasil segue o movimento 
histórico impulsionado tanto pelos Estados fascistas europeus como pela estruturação dos mecanismos de intervenção do Estado nas questões sociais, no modelo intervencionista do "New Deal".

O período que se segue às experiências ditatoriais, definidas por uma hipertrofia do Executivo com relação aos demais poderes, é sempre um período de redefinição e restauração de funções para os poderes Legislativo e Judiciário. No caso do Brasil, como outros países da América Latina, a ditadura militar voltaria a instalar-se na segunda metade do século XX, igualmente utilizando-se de mecanismos de intervenção no Legislativo e no Judiciário, para reduzir-lhes sejam as competências, sejam as garantias, e ainda, no caso do Judiciário, o número de magistrados nos Tribunais. Costa (2006) e Santos (2009) registram as intervenções sofridas pelo Poder Judiciário no Brasil durante os dois períodos ditatoriais.

Assim, a questão da discussão sobre o que compete ao Judiciário surge sempre que se chega ao fim de regimes ditatoriais, com o ressurgimento de regimes democráticos. Analisando o papel do juiz nas novas democracias advindas no pós-Segunda Guerra, Barak (2006, p. XII) afirma que tem havido um incremento na compreensão do que seja a atividade de julgar: "o povo cada vez mais se volta para o Judiciário esperando que este resolva problemas sociais prementes". No período de redemocratização do Brasil, após a ditadura militar, a constituinte de 1986-88 acolheu grandes demandas sociais, políticas e jurídicas que configuraram nossa atual Constituição. O Judiciário amplia-se, com a criação do STJ, e a restauração das garantias e competência, assegurada pelo princípio da universalidade da jurisdição. As funções essenciais à Justiça também são incrementadas, destacando-se a autonomia do Ministério Público e a criação da Advocacia Geral da União e da Defensoria Pública.

É nesse contexto que se encontram o discurso de efetivação de direitos fundamentais e novo papel do judiciário. O Judiciário pretende tornar-se o poder que realmente possa assegurar essas conquistas constitucionalmente declaradas. Constrói-se o pensamento de um Judiciário acessível e próximo do povo. Em meados da década de 90 do século passado, um grupo de pensadores, dos quais se podem citar Tércio Sampaio Ferraz Júnior, José Reinaldo de Lima Lopes, Maria Tereza Sadek e José Eduardo Faria, reúnem estudos (a citar, o Dossiê Judiciário - USP) que defendem o Judiciário efetivamente como um poder de transformação social, capaz de dirimir conflitos de natureza não apenas jurídica, mas política.

Entretanto, cabe questionar, passado 20 anos da publicação do Dossiê do Judiciário, se realmente o acesso à justiça tornou-se uma realidade no Brasil e qual foi o Judiciário descoberto por aqueles que foram nele buscar efetivação de direitos, em especial considerando a trajetória histórica de sua gênese, como foi exposta. A justiça, enquanto estrutura burocrática, além de ser denunciada por morosa, revelou-se um instrumento de solução de conflitos dispendioso e pouco eficiente. Como ressalta Santos (2007, p.31), o problema talvez não esteja na burocracia, mas na "ausência de uma burocracia eficaz e independente, no sentido weberiano".

Inicialmente cabe ressaltar que, individualmente, aqueles que se identificam politicamente como pertencentes às minorias tendem a ter acesso ao Judiciário não para dirimir seus conflitos, mas por vias forçadas, ou seja, principalmente pela via da criminalização de sua conduta, por meio da aplicação do direito penal. Wacquant (2013, p.226), em estudo sobre a gestão da miséria e a criminalização da pobreza, afirma a existência de uma onda punitiva, por meio da qual "a instituição carcerária serve, doravante, como principal instrumento da gestão da miséria na América". Punir os pobres tem sido ainda o meio mais utilizado contra aqueles a quem se endereçariam políticas de justiça social. Esses menos favorecidos raramente utilizam o judiciário como mobilizadores ativos. Além disso, como afirma Santos (2007, p.23), esses indivíduos se veem numa busca inviável:

Ficam totalmente desalentados sempre que entram no sistema judicial, sempre que contatam com as autoridades, que os esmagam pela sua linguagem esotérica, pela sua presença arrogante, pela sua maneira cerimonial de vestir, pelos seus edifícios esmagadores, pelas suas labirínticas secretarias etc. Esses cidadãos intimidados e impotentes são detentores de uma procura invisibilizada.

Ressaltando a dificuldade na passagem do mundo ideal (do direito) para o mundo real (espaço das disputas políticas), para Sorj (2004, p.15) a participação do Judiciário tem sido a expressão de seus limites 
para a resolução de problemas que exigem respostas da ordem administrativa, em uma explicitação que só contribui para desestabilizar o Poder Judiciário: "a judicialização do conflito social [...] tem eficácia limitada como instrumento de diminuição da desigualdade social, pois restringem a representação de interesses a nichos, sem uma visão do conjunto da sociedade". Ademais, "fragilizam a política partidária por retirar dos partidos políticos a representação do discurso moral e a elaboração de novas utopias sociais".

Koerner (2013), analisando a recente tendência no Brasil do movimento do Judiciário em prol da moralidade pública, afirma a existência de um consenso irrefletido aliado a um apelo à ação imediata contra a corrupção, exortando a formulação de problemas e novas hipóteses de pesquisa a fim de que se produza um conhecimento mais denso e crítico sobre o Judiciário brasileiro. O pesquisador não deixa de citar a importância do movimento associativo dos juízes no Brasil, nos últimos anos, como um fator relevante para o estabelecimento do cenário de protagonismo político do Judiciário contemporâneo, bem como o papel das elites judiciais e a criação do Conselho Nacional de Justiça (CNJ).

A transformação (o ato de tomar outra forma) de uma estrutura burocrática da envergadura do Poder Judiciário brasileiro deve, pois, ser anunciada com muita cautela. Por outro lado, a transferência de atribuições transformadoras da realidade social brasileira ao Judiciário está ligada a visão que se construiu desse poder como o único confiável, principalmente em face do Legislativo (corrupto) e do Executivo (ineficiente). Uma forma de submeter os estudos e suas afirmações a uma verificação de falseabilidade é indagar como se deu o encontro entre esse anunciado judiciário e as demandas coletivas, instrumentalizadas especialmente por meio da mobilização centralizada nos movimentos sociais.

\section{Movimentos sociais}

O termo "movimento social" surge na Sociologia por volta de 1840, nos estudos de Lorenz Von Stein, que apontava a necessidade de a Sociologia se debruçar sobre os movimentos do proletariado e sobre o comunismo e o socialismo emergentes. Desde então, vários teóricos têm pesquisado e contribuído para a compreensão desse fenômeno social. Várias são as definições do que seriam os movimentos sociais. Para Scherer-Warren (1987, p. 20), movimentos sociais são:

[...] uma ação grupal para a transformação (a práxis) voltada para a realização dos mesmos objetivos (o projeto), sob a orientação mais ou menos consciente de princípios valorativos comuns (a ideologia) e sob uma organização diretiva mais ou menos definida (a organização e sua direção).

De acordo com Scherer-Warren (1987), outros pensadores, como Lenin, Lukács, Touraine e Castoriadis, definiram os movimentos sociais de acordo com seu recorte teórico, mas é possível afirmar que todos têm como base de seus estudos a teoria de Marx, que propunha um "projeto de transformação da estrutura social por meio de uma práxis revolucionária", pois assim seria possível a formação de uma consciência de classe, sendo os movimentos sociais uma das bases para a concretização desse pensamento.

Os movimentos sociais, enquanto objeto de pesquisa, definem-se com referência a outras noções, como as de democracia, sociedade civil, atores políticos, terceiro setor e organizações não governamentais. Para entendê-los, estabeleceu-se todo um léxico, articulado em um tipo específico de discurso. Para Scherer-Warren (2006), a sociedade civil é a "representação de vários níveis de como os interesses e os valores da cidadania se organizam em cada sociedade para encaminhamento de suas ações em prol de políticas sociais e públicas, protestos sociais, manifestações simbólicas e pressões políticas". Esses vários níveis de representação de interesses e valores podem ser identificados no associativismo local (associações civis e movimentos comunitários), nas formas de articulação interorganizacionais (fóruns da sociedade civil) e nas mobilizações na esfera pública. As mobilizações são fruto da articulação de atores dos movimentos sociais localizados, das ONGs, dos fóruns e redes de redes, e buscam aglutiná-los e transcendê-los, segundo Scherer-Warren (2006), por meio de "manifestações na praça pública, incluindo 
a participação de simpatizantes, com a finalidade de produzir visibilidade através da mídia e efeitos simbólicos para os próprios manifestantes (no sentido político-pedagógico) e para a sociedade em geral", sendo assim "uma forma de pressão política das mais expressivas no espaço público contemporâneo". Em todo caso, trata-se, sempre, de uma busca coletiva, que ressalte e adense os laços de solidariedade social, a perspectiva comunitária e associativa, numa dimensão de empoderamento político.

Touraine (1994) insere a temática dos movimentos sociais na compreensão da democracia. Para ele, não há democracia sem atores políticos que sejam capazes de exprimir exigências, reações e protestos, formando a sociedade civil. A democracia deve ter bases sociais sólidas, para que haja uma correspondência entre exigências sociais e ofertas políticas. Bases sociais se consolidam em meio a conflitos e antagonismos. São os movimentos sociais que ordenam esses conflitos e antagonismos, construindo orientações para a ação política coletiva. Os movimentos sociais cumprem a função de agregar interesses que tendem a dispersão, e que precisam, assim, de uma articulação política que Ihes viabilize o alcance.

Tal afirmação pressupõe que esses interesses se deixam representar, aceitando as regras do jogo político. Isto porque, segundo ainda Touraine (1994), há mobilizações coletivas que são o resultado do impulso radical, ou revolucionário, dirigido contra as instituições que, segundo entendem, são comprometidas com os interesses dominantes. Em virtude desse comprometimento, somente por meio da violência é possível qualquer mudança social. Tal ação coletiva, entretanto, não teria inspiração democrática, por isso Touraine (1994, p.85) as distingue dos movimentos sociais, sendo esse o seu diferencial: movimentos sociais são "ações coletivas que visam modificar o modo de utilização social de recursos importantes em nome de orientações culturais aceitas na sociedade em questão". Movimentos sociais e democracia são, dessa forma, indissociáveis, uma vez que o movimento social é "civil e é uma afirmação antes de ser uma crítica e uma negação. É por isso que ele pode servir de princípio de reconstrução refletida, discutida e decidida de uma sociedade[...]" (TOURAINE, 1994, p. 87).

Afirmando a existência de novos movimentos sociais, Touraine (1994, p. 212) lembra ainda que "os movimentos sociais da época industrial estão esgotados e que novos movimentos sociais se formam tão lentamente e tão dificilmente como o movimento operário do século XIX". As pesquisas sobre novos movimentos sociais no Brasil localizam sua gênese na década de 1980. Para Carlos (2011), são movimentos institucionalmente inseridos, que combinam uma estrutura organizacional mais complexa e relações com instituições políticas e outros movimentos, ou entidades, não institucionais. Partindo do reconhecimento de que a multiplicação de instituições participativas de elaboração de políticas públicas propiciou, no contexto brasileiro pós-88, novas oportunidades de participação e representação no desenho das políticas e na regulação da ação governamental, Carlos (2011) afirma que essa ampliação nas arenas de acesso à institucionalidade política desafiou os atores coletivos para novas práticas e relações com o Estado. Tudo em meio a uma sociedade civil complexa e heterogênea.

Os novos movimentos sociais se caracterizam por ser um processo de reelaboração e ressignificação da relação sociedade-Estado, oscilando entre o discurso de cooperação e contestação, de forma que os movimentos sociais não teriam um padrão de ação coletiva, podendo desenvolver, circunstancialmente, diferentes ações e combiná-las de forma diversa: são protestos públicos, ações formais e alianças com políticos e com a Igreja católica, partidos e agências do Estado. Não há, entretanto, menção a ações junto ao Poder Judiciário. O Judiciário não é referido como um canal de mediação sociedade-Estado.

Essa conclusão é mais compatível com a proposta da instalação de práticas democrática no Brasil, de resto marcado por estruturas autoritárias em uma sociedade conservadora. O processo de construção da democracia brasileira não está sendo, entretanto, sem resistências e dilemas. Ao contrário, como bem ressalta Dagnino (2004, p.96), nos anos noventa houve um trânsito da sociedade civil para o Estado. Como consequência, durante esse mesmo período, "o confronto e o antagonismo que tinham marcado profundamente a relação entre o Estado e a sociedade civil nas décadas anteriores cederam lugar a uma aposta na possibilidade da sua ação conjunta para o aprofundamento democrático". Ora, essa aposta 
demanda um contexto no qual o princípio de participação da sociedade se torna central, o que determina a criação de espaços públicos onde o poder do Estado pudesse ser compartilhado com a sociedade. Um projeto de governo que requer uma sociedade civil ativa e propositiva, e não dependente de soluções estatais, por isso Dagnino (2004) analisa o dilema que se instala: um dilema que questiona o próprio papel político dos movimentos sociais institucionalizados.

Segundo a autora, o risco percebido é que "a participação da sociedade civil nas instâncias decisórias, defendida pelas forças que sustentam o projeto participativo democratizante como um mecanismo de aprofundamento democrático e de redução da exclusão" possa acabar servindo aos objetivos do projeto de redução do Estado pelo encolhimento das responsabilidades sociais do Estado, transferidas para o "terceiro setor".

Embora se instalem nos discursos sobre um novo Judiciário no Brasil os termos "justiça social", "transformação da sociedade" e "atuação no campo das disputas políticas", pela pesquisa empreendida pode-se afirmar que pouco se faz referência ao Judiciário nos estudos das novas feições e ações dos movimentos sociais. Embora a pesquisa realizada não seja exauriente, tem-se uma perspectiva afirmativa da autonomia e autogestão de conflitos por esses movimentos. Poderiam ainda ser problematizadas outras questões, como a natureza política de uma decisão sobre desapropriação, por exemplo, em uma ação judicial individual. O objetivo dessa pesquisa, entretanto, foi o de dar voz aos movimentos sociais. A revisão de literatura feita traduziu o significado da crescente relevância concedida, seja aos movimentos sociais, seja ao Judiciário, na agenda de pesquisa sobre a democracia no Brasil. Trata-se agora de cumprir os objetivos empíricos da pesquisa.

\subsection{Ouvindo os movimentos sociais no Ceará}

Para compreender melhor a relação dos movimentos sociais com o Judiciário, ampliando a perspectiva teórica estabelecida, foram escolhidos três movimentos que desenvolvem suas atividades no Ceará: o "CEARAH Periferia", o coletivo "Quem Dera Ser um Peixe" e o Movimento Sem Terra (MST) Ceará. Dessa maneira, busca-se analisar se e como esses movimentos vão ao Judiciário e como suas demandas são, ou não, atendidas.

Trata-se de amostragem por conveniência, uma vez que a população da pesquisa foi determinada em consideração a sua amplitude de atuação e representatividade, além de facilidade de acesso verificada em pesquisa exploratória inicial. Os dados foram obtidos por meio de aplicação de questionário semiestruturado, gravados em áudio para posterior transcrição e análise crítica. Os sujeitos da pesquisa foram entrevistados pela assistente da pesquisa, co-autora deste artigo, sob a orientação da pesquisadora.

Os questionários foram aplicados no dia 03 de março de 2015, na sede da Faculdade de Direito da Universidade Federal do Ceará e na sede do CEARAH Periferia. Registre-se que a facilidade de acesso verificada em pesquisa exploratória revelou-se limitada, pois por meio das entrevistas estabeleceu-se uma fala com dados poucos precisos. Entretanto, foi acordado em manter a metodologia escolhida ao tempo do projeto (entrevistas por meio de questionário semi-estruturado), buscando completar os dados colhidos nos discurso durante as entrevistas com pesquisa junto aos sites dos movimentos e outras fontes de notícias.

O CEARAH Periferia (Centro de Estudos, Articulação e Referência sobre Assentamentos Humanos) é uma organização não governamental, fundada em 15 de março de 1991. Enquanto movimento social, conceitua-se como instrumento de transformação social e atua principalmente na cidade de Fortaleza e em sua região metropolitana, cuja ação se orienta para garantir uma ocupação urbana digna, por isso sua missão é voltada para o desenvolvimento urbano integrado, sustentável e solidário, assim tendo como objetivos: contribuir para democratização do planejamento urbano por meio da integração de políticas de desenvolvimento urbano e capacitar os movimentos sociais para o exercício de uma cidadania autônoma. 
Nesse contexto, o CEARAH Periferia trabalha como alicerce para garantia de moradias, não se preocupando apenas com as questões estruturais e econômicas de cidadãos que precisam de um lar, mas também com o aspecto social, psicológico e pedagógico das famílias que são atingidas pelos programas habitacionais desenvolvidos pela entidade em parceria com o Estado. Para tanto, a equipe da ONG é multidisciplinar, composta de pedagogos, sociólogos, assistente social, advogados e engenheiros. Busca garantir que a população não seja apenas beneficiada por um programa de moradia, mas receba apoio e acompanhamento durante todo o processo de implementação dos projetos habitacionais, desde o planejamento da obra, cadastro de pessoas que podem ser beneficiadas e construção até a entrega dos imóveis.

Dessa feita, para garantir a concretização das demandas sociais que chegam até o CEARAH Periferia, o movimento busca resolver seus conflitos por via política, buscando sempre dirimir as lide por um meio conciliatório, sendo o Judiciário apontado como uma última alternativa, pois não o veem como uma via de acesso rápido para alcançar seus propósitos. Durante a entrevista, o advogado da instituição informou que o que costuma ser levado ao Judiciário são ações de usucapião. Além disso, os advogados que atuam juntos à organização acabam se envolvendo muito mais em ações preventivas de regularização de moradias e de famílias ameaçadas de remoção, sendo os casos mais complexos entregues à Defensoria Pública. Não foram relatados casos de ações coletivas.

O coletivo "Quem Dera Ser um Peixe" surgiu de um sentimento de indignação de fortalezenses que se mostraram contrários à construção do "Acquario", projeto do governo do Estado sediado no litoral da capital cearense. Os primeiros passos para a construção desse movimento foram realizados por meio do Facebook, ilustrados por fotos do terreno já limpo onde seria construído o "Acquario". A partir de então, vários cidadãos se mobilizaram contra a obra e também passaram a lutar por outros aspectos sociais, como por uma maior participação popular nas decisões de gestão governamental e por uma lógica ambiental sustentável para a orla marítima da cidade de Fortaleza. Definem-se como um "movimento plural que envolve uma série de profissionais e artistas de várias áreas que empregam seus conhecimentos e artes na busca pela transparência". O coletivo congrega outros movimentos, como o "Na rua não estamos só", uma plataforma virtual para monitorar violações de direitos humanos cometidas pelo Estado nas manifestações relacionadas à Copa do Mundo em Fortaleza (CE). Por meio da pesquisa junto ao site do coletivo, verificou-se o uso recorrente de ferramentas como as hastags (\#investigaAcquario e \#plantãoglubglub) e uma linguagem despojada, próprias de novos movimentos sociais, como visto na proposta: "O Quem Dera Ser Um Peixe te ajuda a entender os motivos pra Fortaleza cair fora dessa grande cilada que é o Acquario do Ceará".

Dessa maneira, o movimento tem como objetivos manter a sociedade informada sobre as irregularidades da obra, além de fazer movimentações culturais e informativas na Praia de Iracema. Nessa perspectiva, componentes da organização pesquisaram e estudaram aspectos importantes da obra, como a escolha da empresa para construção, o orçamento divulgado pelo governo, se houve, ou não, processo licitatório, além de realizarem debates e participarem de discussões acerca do empreendimento.

De acordo com o relato colhido em entrevista, ao acessar o Judiciário, o movimento não vem conseguindo alcançar seus objetivos, além de ter integrantes punidos por acionarem o Estado juiz, como o caso de uma condenação em virtude de litigância de má-fé, conforme sentença proferida em primeiro grau. Esse acesso se deu por meio de uma ação popular ajuizada por dois integrantes do movimento. Os advogados que acompanham o processo fazer parte da RENAP (Rede Nacional de Advogadas e Advogados Populares). Segundo o entrevistado, nessa lide, o juiz deu causa ganha ao Estado do Ceará, reconhecendo a legalidade da construção. Além dessa ação, o "Quem Dera Ser um Peixe" sempre buscou parceria com o Ministério Público, Federal e Estadual, no intuito de acompanhar e colaborar com as investigações que são realizadas pelo órgão público acerca da construção do Acquario. O movimento também apoia a instalação de CPI junto à Assembleia do Estado para investigar os procedimentos da construção. 
O Movimento Sem Terra (MST) iniciou suas ações nos anos 80 do século passado, em um contexto histórico delicado, devido à situação política vivida no Brasil naquele momento. O movimento propunha uma reforma agrária em pleno regime militar. Logo em seguida, no contexto de redemocratização do país, o movimento começa a alcançar seu objetivo por meio do PNRA (Plano Nacional da Reforma Agrária). Hoje, o MST é um movimento de massa que não se atém apenas à reforma agrária, mas também à transformação social das famílias envolvidas no movimento.

No total, hoje são cerca de 350 mil famílias que conseguiram conquistar um pedaço de terra por meio da luta e da organização desses trabalhadores rurais. Além disso, o MST está presente em 24 estados nas cinco regiões do Brasil, e o Ceará é um desses estados. Vale ressaltar ainda que o movimento é organizado, dividindo-se em setores para melhor atingirem seus objetivos: frente de massa, formação, educação, produção, comunicações, projetos, gênero, direitos humanos, saúde, finanças e relações internacionais. Dessa forma, a luta não se extingue com a conquista de uma propriedade, mas com a transformação da sociedade.

Apesar da história e das conquistas desse movimento, com relação à resolução de litígios perante o Judiciário, pode-se afirmar que o MST tem uma trajetória tumultuada. Segundo o entrevistado, o movimento não aciona o Judiciário com frequência, e sim busca resolver seus litígios por via política, com ações de massa para conseguirem seus objetivos. No entanto, a ida de membros do movimento pela via forçada é algo significativo, principalmente durante as ocupações e acampamentos realizados pelo movimento. Visitas ao site do MST dão conta de tentativas de assassinato e ataques aos acampamentos.

\section{Conclusão}

Após as reflexões realizadas neste trabalho, juntamente com as entrevistas concedidas, chega-se no momento de tentar responder os questionamentos propostos no início da pesquisa.

As articulações que sustentam os movimentos sociais são bastante complexas. Torná-las demandas jurídicas nem sempre é possível, nem sempre é desejável. A tarefa reservada ao Judiciário em um Estado de direito não engloba a resolução de questões sociais que sejam profundas, derivadas mais da estrutura do que da conjuntura, o que exige ações conjuntas do Estado e da própria sociedade.

O Estado, nesse caso, atua prioritariamente por meio de políticas públicas, que possibilitam mudanças nem sempre perceptíveis de forma imediata, mas que são aptas a sustentar transformações de longa duração. O protagonismo do Judiciário revela-se mais prejudicial à instalação de formas democráticas sólidas do que benéfico para resolução das demandas dos movimentos sociais.

Foi verificado que a maioria dos problemas solucionados pelos movimentos entrevistados obteve êxito por vias paralelas à atividade jurisdicional, por meio do recurso ao diálogo político, parcerias com outras instituições e velhas formas de pressão, com pessoas saindo às ruas e exigindo do governo resolução de suas demandas. Além disso, como desvelado pelos relatos das entrevistas, os movimentos sociais veem o Judiciário como um poder a ser acionado quando todas as outras vias falharem. Especialmente no caso do MST, o cenário de afastamento se agrava, pois muitos dos seus membros vão a esse poder por via forçada, muitas vezes por ações criminais devido a sua atuação no campo em defesa dos direitos da coletividade.

Pelo que foi colhido durante a pesquisa, o encontro entre Judiciário e movimentos sociais ainda é uma ficção. Por outro lado, é possível concluir que a judicialização dos conflitos sociais não é a melhor solução para o atendimento de demandas formuladas junto aos movimentos sociais em uma democracia, pois tais soluções, além de terem uma eficácia muito limitada, reduzem a representação de interesses a nichos, fragilizando uma visão em conjunto da sociedade e problematizando a repartição de competência entre os poderes instituídos constitucionalmente. 


\section{Referências}

ALENCASTRO, Luiz Felipe de. 0 trato dos viventes: formação do Brasil no Atlântico Sul. São Paulo: Companhia das Letras, 2000.

BARAK, Aharon. The judge in a democracy. Princeton: Princeton University Press, 2006.

CARLOS, Euzeneia. Movimentos sociais: revisitando a participação e a institucionalização. Lua Nova, São Paulo, v. 84, p. 315-348, 2011.

CARVALHO, José Murilo de. A construção da ordem: a elite política imperial. Teatro das sombras: a política imperial. Rio de Janeiro: Civilização Brasileira, 2003.

CENTRO DE ESTUDOS, ARTICULAÇÃO E REFERÊNCIA SOBRE ASSENTAMENTOS HUMANOS CEARAH Periferia. Disponível em: < http://www.cearahperiferia.org.br/>. Acesso em: 16 mar. 2015.

CONTRA o aquário. Disponível em: <https://pt-br.facebook.com/contraoaquario> Acesso em: 16 mar. 2015.

COSTA, Emília Viotti da. O Supremo Tribunal Federal e a construção da cidadania. 2. ed. São Paulo: UNESP, 2006.

DAGNINO, Evelina. Sociedade civil, participação e democracia: do que estamos falando? In: MATO, Daniel (Coord.). Políticas de ciudadanía y sociedad civil en tiempos de globalización. Caracas: FACES, Universidad Central de Venezuela, 2004. p. 95-110. Disponível em: <http://bibliotecavirtual. clacso.org.ar/Venezuela/faces-ucv/20120723055520/Dagnino.pdf> . Acesso em: 27 ago. 2014.

FARIA, José Eduardo. Os desafios do Judiciário. Revista USP, São Paulo, n. 21, p. 46-57, mar./maio 1994.

KOERNER, Andrei. Judiciário e moralização da política: três reflexões sobre as tendências recentes no Brasil. Pensar - Revista de Ciências Jurídicas, Fortaleza, v. 18, n. 3, p. 681-711, set./dez. 2013.

MOVIMENTO DOS TRABALHADORES SEM TERRA. Disponível em: <http://www.mst.org.br/ > Acesso em: 16 mar. 2015.

SANTOS, Boaventura de Sousa. Para uma revolução democrática da justiça. São Paulo: Cortez, 2007.

SANTOS, Marcelo Paiva dos. A história não contada do Supremo Tribunal Federal. Porto Alegre: Sérgio Antônio Fabris, 2009.

SCHERER-WARREN, Ilse. Movimentos sociais. Florianópolis: EDUFSC, 1987.

SCHERER-WARREN, Ilse. Das mobilizações à redes de movimentos sociais. Sociedade e Estado, Brasília, v. 21, n.1, p. 109-130, jan./abr. 2006.

SCHWARTZ, Stuart B. Burocracia e sociedade no Brasil colonial: o Tribunal Superior da Bahia e seus desembargadores, 1609-1751. Tradução de Berilo Vargas. São Paulo: Companhia das Letras, 2011.

SORJ, Bernardo. A democracia inesperada: cidadania, direitos humanos e desigualdade social. Rio de Janeiro: Jorge Zahar, 2004.

TERRE DE DIREITOS. Organização de direitos Humanos. Disponível em: <http://www.renap.org.br/>. Acesso em: 16 mar. 2015.

TOURAINE, Alain. O que é a democracia? Tradução de Fernando Tomaz. Lisboa: Instituto Piaget, 1994.

WACQUANT, Loïc. Punir os pobres: a nova gestão da miséria nos Estados Unidos [A onda punitiva]. Tradução de Sérgio Lamarão. 3. ed. Rio de Janeiro: Revan, 2013.

Recebido em: 26/03/2015.

Aprovado em: 25/08/2016. 